\title{
Morals, medicine and geography
}

$\mathrm{T}$ he US government recently proposed a rule that will force hundreds of thousands of health agencies to prove that they are not compelling doctors to perform or make referrals for - or even provide clinical information about - controversial procedures like abortion and sterilization.

Health policy changes north of the 49th parallel suggest Canada is heading in a different direction.

Doctors in both countries have been prompted by new guidelines to reconsider the effects of restricting physicians' freedom of conscience. Some believe it will demoralize a segment of the profession and drive many to seek new careers. Others claim that patients' rights to access legal services make restrictions necessary.

The latter argument appears to be the one favoured by the College of Physicians and Surgeons of Ontario, which in September approved a new policy: Physicians and the Ontario Human Rights Code. "Compliance with the Code is one factor the College will consider when evaluating physician conduct," states the policy, which lists 4 things the college expects of all Ontario doctors, regardless of their moral or religious beliefs: that they be upfront about the services they don't provide, that they inform patients of all their clinical options, that they not promote their religious beliefs, and that they advise patients to see other doctors in certain situations. The Alberta College of Physicians and Surgeons has drafted a similar policy.

This stands in stark contrast with a rule proposed by the US Department of Health and Human Services on Aug. 21 which will require all health care institutions that receive federal funding to certify in writing that they are following existing nondiscrimination laws. These laws, some of which date back to the 1970s, prohibit discrimination against doctors who refuse to "counsel, suggest, recommend, assist, or any way participate" in procedures that offend their moral or religious sensibilities.

"This regulation does not limit patient access to health care, but rather protects any individual health care provider or institution from being com- pelled to participate in, or from being punished for refusal to participate in, a service that, for example, violates their conscience," states the rule, which will affect almost 600000 health entities and cost an estimated $\$ 44.5$ million a year to implement. Institutions that violate the rule may lose funding or be forced to return funds already received.

The new policy in Ontario is primarily a precautionary measure, a response to changes at the Ontario Human Rights Commission that will make it easier for patients to bring discrimination charges against doctors. The College also claims it was prompted by a need to clarify human rights obligations and the professional expectations of its members because of direct complaints it had already received.

The response has been swift and

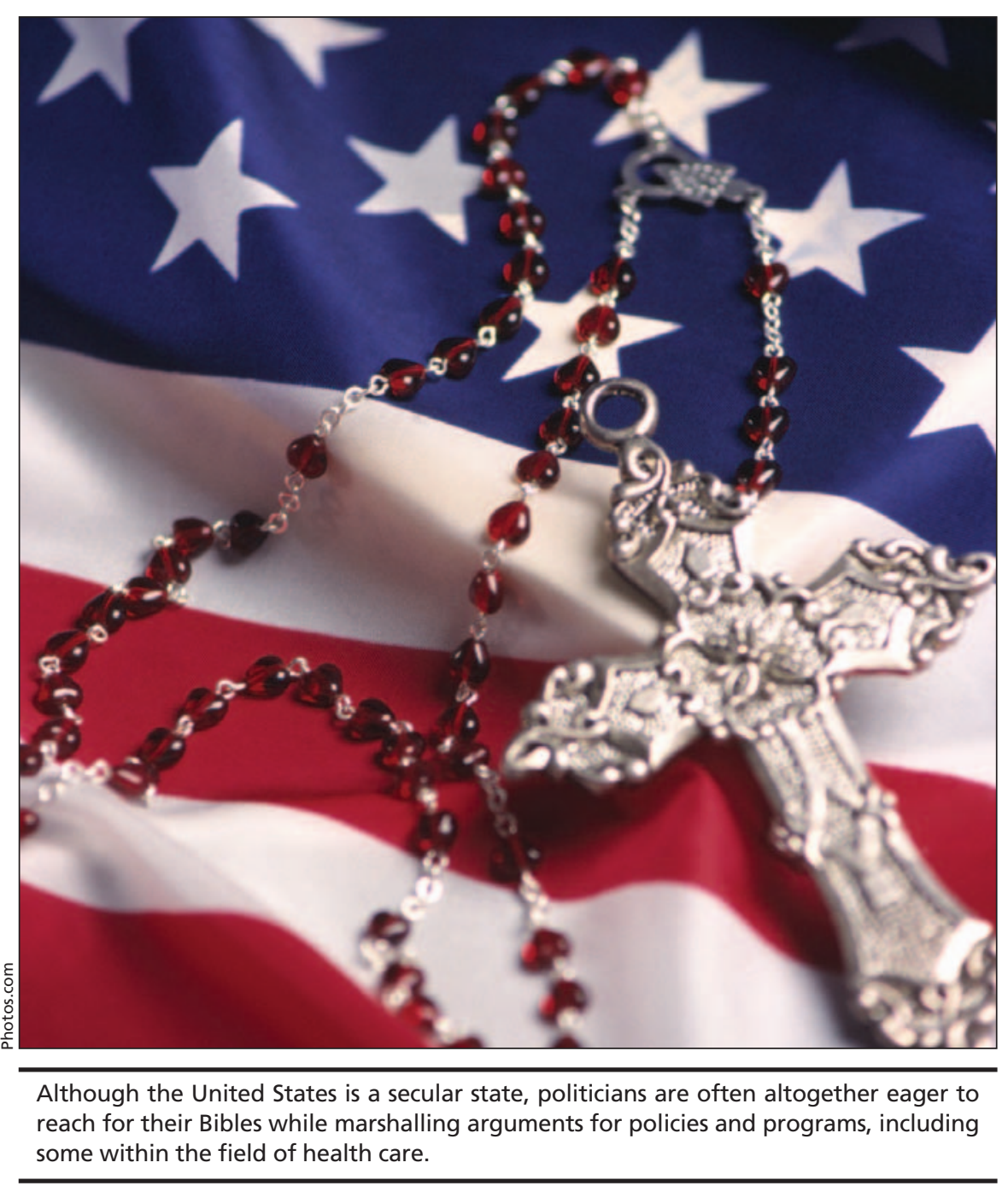

Although the United States is a secular state, politicians are often altogether eager to reach for their Bibles while marshalling arguments for policies and programs, including some within the field of health care.

abundant. The Ontario Medical Association asserted that "it should never be professional misconduct for an Ontario physician to act in accordance with his or her religious or moral beliefs."

Ethicists and doctors soon weighed in, raising difficult philosophical questions: Is a doctor primarily a caretaker of the sick or a facilitator for consumers of medical services? Will placing limits on the conscientious objections of individual doctors degrade the conscientiousness of the entire profession? Is it ethical for a medical body to compel doctors to be involved in acts they consider morally repugnant?

"For most Canadians, maybe because we don't take religious convictions as seriously, we think the service to the patient is what matters," says Wayne Sumner, a University of Toronto professor emeritus 
of philosophy. "We'll certainly allow some respect for people's moral or religious convictions to compromise that, but we have very definite limits. This distinction between allowing someone not to do it themselves and compelling them to disclose somebody else who would do it strikes me as the Canadian compromise."

There will be no such compromise south of the border, where guidelines were issued because of concerns that certain medical bodies were misinterpreting or even ignoring the long-standing physician discrimination laws. Proponents of the new rule believe this was apparent from the many recent statements in published medical literature, including one from the American College of Obstetricians and Gynecologists, claiming doctors are obligated to make referrals even for procedures they oppose.

"That is a change, a pretty striking one," says Dr. Farr Curlin, an assistant professor of medicine and associate at the University of Chicago's MacLean Center for Clinical Medical Ethics. "There's never been a time, either in the professional ethical literature and certainly in policy, that doctors have had an obligation to refer or participate in any way in practices just because they are legal. Doctors have an obligation to maintain their integrity."

In 2003, Curlin, an internist by training, conducted the first national survey of American doctors' religious beliefs. The results indicated that doctors were surprisingly religious: $90 \%$ attended religious services, at least occasionally, compared to $81 \%$ of the public (JGIM 2005;20[7]:629-34). Slightly more than half of the 1144 doctors who responded to the survey said their religious beliefs influence how they practice.

A substantial portion of respondents objected to certain medical services: $53 \%$ opposed abortion for failed contraception, for example, and $42 \%$ opposed prescribing birth control for adolescents without parental consent ( $N$ Engl J Med 2007;356[6]:593-600). Still, 86\% of survey participants believed doctors were obligated to present patients with all clinical options, and $71 \%$ believed doctors were obligated to refer patients to someone who would perform the services. Religious participants, however, were more likely to be among the minorities that be- lieved they had no such obligations.

Curlin is not surprised that the medical profession appeals to religious believers. Tending to the sick, he says, is among the highest callings in all moral and religious traditions. Though there is no data on the religious beliefs of Canadian doctors, it stands to reason that a more secular nation would produce fewer religious doctors.

Though Judeo-Christian values permeate the American conscience, the new US rule, like the Ontario policy, has its share of critics. In a New York Times opinion piece, US Senator Hillary Clinton condemned the rule, claiming that "quality care for millions of women is at stake." The American Psychiatric Association and the American Academy of Pediatrics also expressed opposition to the new guidelines, as did attorneys general from 13 states.

Catholic and evangelical organizations have voiced support for the rule, while atheist philosopher Crispin Sartwell argued that many of the worst atrocities in histories occurred because ruling institutions forced individuals to resign their conscience.

"What conscientious refusal does, and this is healthy for any public order, is create a moment where people have to recognize that there are choices and that those choices have consequences," says Curlin. "You take that away and everyone has to do whatever the state mandates. That will make people feel helpless. They will be more apathetic and take less responsibility. ... It's a Faustian bargain; you're losing more than you gain."

Advocates of compulsory referral claim that doctors who discriminate against certain practices are, whether they know it or not, also discriminating against certain people - namely, the poor, the uneducated and those in remote areas. These people already have limited access to medical services, a problem that, all sides agree, is exacerbated when their doctors refuse to present them with all their options.

Another danger of unrestricted faithguided medical practise, some claim, is that it allows doctors to refuse services to patients based on arbitrary social judgments about lifestyle and behaviour. This was the crux of the recent discrimination case brought against a California

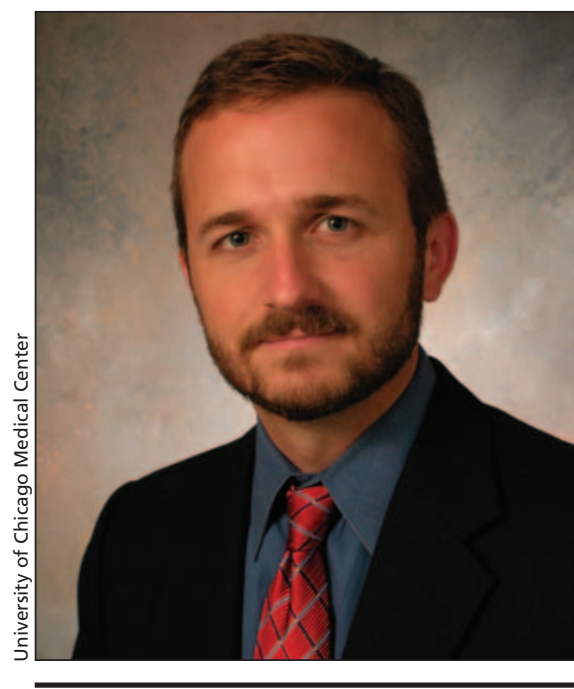

It's no surprise that physicians are often highly religious, given that tending the sick is viewed as a high ethical calling, says University of Chicago internist Dr. Farr Curlin.

medical clinic that refused to perform an artificial insemination on a lesbian. On Aug. 18, the California Supreme Court ruled against the clinic, stating that its doctors were not permitted to discriminate against patients because of their sexual orientation.

This type of situation, however, is less likely to occur in Canada, says Kerry Bowman, an assistant professor at the University of Toronto's Joint Centre for Bioethics. "The duty to care is very powerful in Canada, and I think it should be quite narrow as to what situations you would refuse treatments to a patient."

Still, Bowman says, it is important to encourage moral reflection in health care, particularly as new reproductive and genetic technologies push medicine into uncharted ethical waters.

"It is a shame that there is a lot more heat than light with these discussions," says Curlin. "The reality is that there is a real disagreement about what is good and what it means for a doctor to fulfill his or her obligations. It can't be easily resolved by saying doctors should focus on their professional obligations and not their personal values, because the issue is: what are our professional obligations? ... There is no consensus on that, and there's not going to be anytime soon." - Roger Collier, CMAJ

DOI:10.1503/cmaj.081626 